\title{
Multilevel Logistic Regression Analysis of Intimate Partner Violence and Its Associated Factors in Ethiopia
}

Mekuanint Simeneh Workie ( $\sim$ mekuanintsimeneh@gmail.com )

Research article

Keywords: Intimate Partner Violence, Women, Ethiopia, Factors, Multi-level

Posted Date: March 2nd, 2020

DOI: https://doi.org/10.21203/rs.3.rs-15571/v1

License: (c) (1) This work is licensed under a Creative Commons Attribution 4.0 International License.

Read Full License 


\section{Abstract}

Background Intimate Partner Violence is a great public health concern with economic, physical, mental, sexual and reproductive health consequences. Therefore, the aim of this study was to assess the prevalence of intimate partner violence against women and associated factors in Ethiopia.

Methods A secondary data analysis was carried out based on the Ethiopia Demographic and Health Survey 2016. Both single and multilevel logistic regressions were employed.

Results Among ever-married women (15-49 years old) who have been participated in this study, $22.3 \%$, $7.6 \%$ and $6.1 \%$ of women have experienced emotional, sexual and physical violence respectively. The prevalence of intimate partner violence was found to be $25.6 \%$. Partner's desire for children, number of living children, women ever chewed chat, husband/partner drinks alcohol, respondent's occupation, number of other wives, type of place of residence were found to be significant determinants of intimate partner violence.

Conclusion More than 1 in 4 ever married women in Ethiopia have experienced violence from their intimate partners. The government's effort towards elimination of violence against women should be well strengthened by addressing intimate partner violence disparity in Ethiopian regions and also taking in to account other identified factors of intimate partner violence in this study.

\section{Background}

Intimate partner violence(IPV) is defined by any act of physical aggression, sexual coercion, psychological abuse and controlling behaviors within an intimate relationship[1]. It is inevitable elsewhere in the world[2]. Globally, nearly one third(30\%) of women have experienced violence during their lifetime from an intimate partner of which, Africa shares $36.6 \%$ of this figure [3]. In Ethiopia, about $20 \%$ to $78 \%$ of women encountered intimate partner violence [4]. It has an effect on the productivity, physical, mental, sexual and reproductive health of women [5-9].

Besides putting the legal and policy provisions in its Constitution, Ethiopia has ratified international and continental agreements that promote and protect the rights of women and girls, including the Convention on the Elimination of Discrimination against Women[10], and the Protocol to the African Charter on the Rights of Women in Africa[11]. Moreover, to address violence, Ethiopia has also established the Revised Family Law in 2000 and the Revised Criminal Code in 2004[12]. The Second Growth and Transformational Plan (GTP II 2015) of Ethiopia has for the first time set a priority to end violence against women [13].

Despite these initiatives and efforts, the prevalence of IPV is still not declining significantly as expected. The studies conducted on intimate partner violence against women are lacking as existing focus on specific geographic locations. A related country wide data are needed to better inform and educate the policy makers, programmers, implementers and the general population about the problem. Therefore, the 
aim of this study was to assess the prevalence of intimate partner violence against women and associated factors in Ethiopia.

\section{Methods}

A secondary data analysis was carried out based on the Ethiopia Demographic and Health Survey 2016[14] after getting online permission from Measure DHS website.

The analysis focused on ever married women in the age range of 15-49 years old. Violence committed by her intimate partner was measured as (1) Emotional spousal violence: say or do something to humiliate you in front of others; threaten to hurt or harm you or someone close to you; insult you or make you feel bad about yourself;(2)Physical spousal violence: push you, shake you, or throw something at you; slap you; twist your armor pull your hair; punch you with his/her fist or with something that could hurt you; kick you, drag you, or beat you up; try to choke you or burn you on purpose; or threaten or attack you with a knife, gun, or any other weapon;(3) Sexual spousal violence: physically force you to have sexual intercourse with him even when you did not want to; physically force you to perform any other sexual acts you did not want to; force you with threats or in any other way to perform sexual acts you did not want to[14]. Intimate partner violence was ascertained when the women had experienced at least one form of violence among the three by their intimate partner in their life time.

In this study, both single and multilevel logistic regressions were employed. The response variable of the study was intimate partner violence prior to the survey. Firstly, we analyzed using single level binary logistic regressions by assuming the occurrence of intimate partner violence is independent among ever married women. And finally, we assessed the effect of determinant factors and regional difference on prevalence of intimate partner violence using multilevel logistic regression model.

\section{Multilevel logistic regression model}

Multilevel models are statistical models which allow not only independent variable at any level of hierarchical structure but also at least one random effect above level one group[15].A multilevel logistic regression model can account for lack of independence across levels of nested data (i.e. ever married women nested within regions). The multilevel models are used to assess whether the effect of predictors vary from region to region. The binary multilevel logistic regression model has a binary outcome (intimate partner violence (yes/no)). In this study, the basic data structure of the two-level logistic regression is a collection of $\mathrm{N}$ groups (regions) and within-group $j(j=1,2, \ldots, N)$, a random sample $\mathrm{n}_{\mathrm{j}}$ of level-one units (ever married women).

The response variables is $Y_{i j}=1$ if the $\mathrm{i}^{\text {th }}$ ever married women in $\mathrm{j}^{\text {th }}$ region has intimate partner violence, and $\mathrm{Y}_{i j}=0$ otherwise; with probabilities, $\mathrm{P}_{i j}=\mathrm{P}\left(y_{i j}=1 \mid \mathrm{X}_{i j}, u_{j}\right)$, is the probability of having intimate partner violence for ever married women $i$ in region $j$ and $u_{j}$ is a random cluster effect. Testing heterogeneity of proportions: For the proper application of multilevel analysis, the first logical step is to 
test heterogeneity of proportions between groups. Here we present two commonly used test statistics that are used to check for heterogeneity. To test whether there are indeed systematic differences between the groups, the well-known chi-square test for contingency table can be used.

\section{Empty model}

The empty two-level model for a dichotomous outcome variable refers to a population of groups (leveltwo units) and specifies the probability distribution for group-dependent probabilities $P_{j}$ in $Y_{i j}=P_{j}+\varepsilon_{i j}$ without taking further explanatory variables into account. The model that specifies the transformed probabilities logit $\left(P_{j}\right)$ to have a normal distribution. This is expressed, for a general link function logit $\left(P_{j}\right)$, by the formula

$\operatorname{logit}\left(\mathrm{P}_{\mathrm{j}}\right)=\beta_{o}+U_{o j}$

where $\beta o$ is the population average of the transformed probabilities and $U_{o j}$ is the random deviation from this average for group $\mathrm{j}[16]$. The fundamental reason for applying multilevel analysis is the existence of intra-class (intraregional) correlation arising from similarity of prevalence of intimate partner violence in the same region compared to those of different regions. The intra-class correlation coefficient (ICC) measures the proportion of variance in the outcome explained by the grouping structure. ICC can be calculated using an intercept only model.The ICC is then calculated based on the following formula:

$$
I C C=\frac{\sigma_{U_{o}}^{2}}{\sigma_{U_{o}}^{2}+\sigma_{e}^{2}}
$$

Where ${ }^{\sigma_{e}^{2}}$ variance of individual (lower) level units. In multilevel logit model, level one residual variance ${ }^{\sigma_{e}^{2}}$ $\approx 3.29[15]$

\section{Random intercept model}

With grouped data, a regression that includes indicators for groups is called a varying-intercept model because it can be interpreted as a model with a different intercept within each group. In this case the random intercept model is consider only random effect of each indicators of intimate partner violence meaning that the region differ with respect to the average value of intimate partner violence, but there is no different relation between indicators of intimate partner violence among groups (regional states). The two-level Binary random intercept model can be rewritten as $[16,17]$

$$
\operatorname{Logit}\left(\mathrm{p}_{\mathrm{ij}}\right)=\beta_{0}+\beta_{1} \mathrm{x}_{1 \mathrm{ij}}+\cdots \beta_{\mathrm{k}} \mathrm{x}_{\mathrm{kij}}+\mathrm{u}_{0 \mathrm{j}}
$$

Where represent $X_{i j}=\left(X_{1 i j}, X_{2 i j} \ldots, X_{k i j}\right)$ are the covariates, $\beta=\left(\beta_{0}, \beta_{1} \ldots, \beta_{k}\right)$ are regression coefficients, $U_{0 j}$ is the random effects of model parameter at level two. It is assumed that the $U_{0 j}$ follow a normal distribution with mean zero and variance ${ }^{\sigma_{e}^{2}}$. By adding a randomly varying slope to the random intercepts model we obtain the random regression coefficients model. A second model, called a random coefficients or random slopes model, allows the coefficients to vary across groups. For this the coefficient 
of intimate partner violence can vary across regions. Usually, though, if we wish the coefficients to vary then we vary them in conjunction with the intercepts. Only rarely does a researcher attempt to design a model with random slopes only. We therefore will consider a model with both random slopes, or coefficients, and intercepts. The general formula for the combined random intercept and slopes model can be expressed as

$$
\operatorname{Logit}\left(\mathrm{p}_{\mathrm{ij}}\right)=\beta_{0}+\sum_{h=1}^{k} \beta_{\mathrm{h}} x_{i j}+u_{0 j}+\sum_{h=1}^{k} \mathrm{u}_{\mathrm{hj}} x_{i j}
$$

The first part ${ }^{\beta_{0}+\sum_{h=0}^{k} \beta_{\mathrm{h}} x_{i j}}$ is called the fixed part of the model, and the second par ${ }^{u_{0 j}+\sum_{h=0}^{k} u_{h j} x_{i j}}$ is called the random part of the model. The random variables or effects, $U_{0 j}, U_{1}, \ldots, U_{\mathrm{k} j}$ are assumed to be independent between groups but may be correlated within groups. So the components of the vector $\left(U_{0 j}\right.$, $U_{1 j}, \ldots, U_{k j}$ are independently distributed as a multivariate normal distribution with zero mean vector and variances and co-variances matrix.

\section{Results}

In this study, a total of 4720 ever married women had been included in the analysis. Some variables were found with missing values and treatment of the missing values was done using missing completely at random technique. About 1 in 4 ever-married women in the age range of 25-34 have experienced intimate partner violence during their life time. More than a quarter of ever-married women living in rural part of Ethiopia have experienced an intimate partner violence during their life time. One thousand and fourteen (24.6\%) of women who were married or living with partner have encountered violence from their intimate partner. Among ever-married women who have been participated in this study, $22.3 \%, 7.6 \%$ and $6.1 \%$ of women have experienced emotional, sexual and physical violence respectively. The prevalence of intimate partner violence was found to be $25.6 \%$ (Table - 1 ). 


\begin{tabular}{|c|c|c|c|}
\hline \multirow[t]{2}{*}{ Variables } & \multirow[t]{2}{*}{ Category } & \multicolumn{2}{|c|}{ Intimate Partner Violence } \\
\hline & & Yes $(\%)$ & No $(\%)$ \\
\hline \multirow[t]{3}{*}{ Age group } & $15-24$ & $243(21.3)$ & 897(78.7) \\
\hline & $25-34$ & $506(25.1)$ & 1506(74.9) \\
\hline & $35-49$ & $458(29.2)$ & 1110(70.8) \\
\hline \multirow[t]{3}{*}{ Religion } & Christian & $750(28.2)$ & 1914(71.8) \\
\hline & Muslim & $431(21.6)$ & $1562(78.4)$ \\
\hline & Other & $26(41.3)$ & $37(58.7)$ \\
\hline \multirow[t]{2}{*}{ Residence } & Urban & $288(23.8)$ & $923(76.2)$ \\
\hline & Rural & $919(26.2)$ & $2590(73.8)$ \\
\hline \multirow[t]{11}{*}{ Region } & Tigray & $145(29.4)$ & $348(70.6)$ \\
\hline & Afar & $60(15.5)$ & $327(84.5)$ \\
\hline & Amhara & $159(27.8)$ & $413(72.2)$ \\
\hline & Oromia & 198(30.5) & $451(69.5)$ \\
\hline & Somali & $40(8.6)$ & $424(91.4)$ \\
\hline & Benishangul Gumuz & $125(32.6)$ & $258(67.4)$ \\
\hline & SNNPR & $137(24.3)$ & $427(75.7)$ \\
\hline & Gambela & 105(30.6) & $238(69.4)$ \\
\hline & Harari & $101(35.9)$ & $180(64.1)$ \\
\hline & Addis Ababa & $65(22.6)$ & $223(77.4)$ \\
\hline & Dire Dawa & $72(24.3)$ & $224(75.7)$ \\
\hline \multirow[t]{2}{*}{ Marital Status } & Married or living with partner & $1014(24.6)$ & $3109(75.4)$ \\
\hline & Widowed or Divorced or Separated & 193(32.3) & $404(67.7)$ \\
\hline \multirow[t]{5}{*}{ Occupation } & Not working & $541(22.8)$ & 1837(77.2) \\
\hline & Employed (salary paid) & $26(15.8)$ & $139(84.2)$ \\
\hline & Merchant & $198(28.1)$ & $506(71.9)$ \\
\hline & Farmer & 295(30.9) & $661(69.1)$ \\
\hline & Other & $147(28.4)$ & $370(71.6)$ \\
\hline \multirow[t]{3}{*}{ Educational level of partner } & No education & $484(24.8)$ & $1469(75.2)$ \\
\hline & Primary & $363(28.2)$ & $924(71.8)$ \\
\hline & Secondary and above & $167(18.9)$ & $716(81.1)$ \\
\hline \multirow[t]{5}{*}{ Wealth quintile } & Poorest & $340(24.1)$ & 1072(75.9) \\
\hline & Poorer & $203(27.8)$ & $526(72.2)$ \\
\hline & Middle & 198(30) & $462(70)$ \\
\hline & Richer & $172(28.2)$ & 2438(71.8) \\
\hline & Richest & $294(22.5)$ & 1015(77.5) \\
\hline \multirow[t]{4}{*}{ Number of living children } & 0 & $101(19.2)$ & $424(80.8)$ \\
\hline & $1-2$ & $420(25.6)$ & $1221(74.4)$ \\
\hline & $3-4$ & $320(25.3)$ & $943(74.7)$ \\
\hline & $5+$ & $366(28.4)$ & $925(71.6)$ \\
\hline \multirow[t]{2}{*}{ Number of other wives } & No other wives & $843(23.7)$ & 2715(76.3) \\
\hline & 1-6 other wives & $171(30.3)$ & $394(69.7)$ \\
\hline \multirow[t]{2}{*}{ Partner drinks alcohol } & No & $723(20.6)$ & $2779(79.4)$ \\
\hline & Yes & $484(39.7)$ & $734(60.3)$ \\
\hline \multirow[t]{2}{*}{ Woman smokes cigarettes } & No & 1181(25.3) & $3484(74.7)$ \\
\hline & Yes & $26(47.3)$ & $29(52.7)$ \\
\hline \multirow[t]{2}{*}{ Woman chewed chat } & No & $1025(24.7)$ & $3126(75.3)$ \\
\hline & Yes & $182(32)$ & $387(68)$ \\
\hline \multirow[t]{3}{*}{ Partner's desire for children } & Both want same & $377(23)$ & $1264(77)$ \\
\hline & Partner wants more & $295(26.6)$ & $815(73.4)$ \\
\hline & Partner wants fewer & $101(36.2)$ & 178(63.8) \\
\hline
\end{tabular}

Page 6/16 
A multiple logistic model was fitted to the data to test the research hypothesis regarding the relationship between the likelihood that intimate partner violence is related with the predictor variables. A result displayed in Table-2 showed that intimate partner violence was significantly associated with geographical regions. The odds of intimate partner violence in Amhara, Oromia, SNNPR, Benishangul Gumuz, Gambela, Addis Ababa and Dire Dawa regions were not significantly different from intimate partner violence in Tigray region. Ever married women in Afar and Somali region have been 0.653 and 0.3084 times less likely to have intimate partner violence than in Tigray region respectively. Also, the finding in Harari region were 2.1759 times more likely to experience intimate partner violence than Tigray region.

Furthermore, findings show the difference in the area of residence related to intimate partner violence against women. It has been found that ever married women living in the rural areas were 1.262 times more likely to have intimate partner violence as compared to those living in the urban areas. Likewise, the result illustrated that ever married women employed (salaried) were 0.5899 times less likely to experience intimate partner violence compared to those not working (Table -2).

Additionally, the result shows that women who were smoking cigarettes were at increased risk of intimate partner violence. Ever married women with smoking cigarettes were 1.913 times more likely to have intimate partner violence compared to those who did not smoke cigarettes. In line with this, it has been found that ever married women who were not living together with their husbands/partners were 1.419 times more likely to have intimate partner violence compared to married or living with partner. In addition, women with their husbands having 1-6 other wives were1.612times more likely to experience violence than women with their husbands have no other wives. Ever married women with partner drinks alcohol were 2.692 times more likely to have intimate partner violence than their counterparts (Table -2).

Besides this, findings show that the log odds of the intimate partner violence for chewed chat. With this, the odds ratio (OR) of chewed chat as compared to that of the not chewed chat is given as $O R=1.33$, which implies that women who chewed chat were $33 \%$ more likely to have intimate partner violence compared to women who were not chewing chat. Women with number of living children 1-2, 5+were 1.366 and 1.692 times more likely to experience intimate partner violence compared to women who had no living children respectively. Husband's desire for children wants fewer were 1.496 times more likely to have intimate partner violence compared to husband's desire for children both husband and woman want same (Table-2).

Table -2: Multiple binary logistic regression models of factors associated with intimate partner violence among ever-married women in Ethiopia, Ethiopia DHS 2016 


\begin{tabular}{l|l|l|l|l|l|l|l|}
\hline zbles & Estimate & S.E. & OR & \multicolumn{2}{|l|}{ Confidence Interval $\left(\mathrm{e}^{\beta}\right)$} & Z- \\
\cline { 5 - 6 } & & & & Lower & Upper & value \\
\hline cept & -2.05926 & 0.19061 & 0.127548 & 0.0874237 & 0.1846011 & -10.804 & $<2 \mathrm{e}-16$ \\
$* * *$ & & & & & \\
\hline
\end{tabular}

Region (ref= Tigray)

\begin{tabular}{|c|c|c|c|c|c|c|c|}
\hline & -0.42618 & 0.1844 & 0.653001 & 0.4527895 & 0.9339428 & -2.310 & $\begin{array}{l}0.02088 \\
*\end{array}$ \\
\hline ara & -0.20944 & 0.1428 & 0.811036 & 0.6130171 & 1.0730595 & -1.467 & 0.14233 \\
\hline aia & 0.23484 & 0.1419 & 1.264704 & 0.9583952 & 1.6717506 & 1.655 & 0.09786 \\
\hline ali & -1.17633 & 0.2062 & 0.308409 & 0.2039295 & 0.4582929 & -5.706 & $\begin{array}{l}1.16 \mathrm{e}- \\
08 * * *\end{array}$ \\
\hline shangul Gumuz & 0.25129 & 0.1582 & 1.285686 & 0.9427332 & 1.7529533 & 1.589 & 0.11206 \\
\hline $\mathrm{PR}$ & -0.10631 & 0.14964 & 0.8991435 & 0.6704136 & 1.2056927 & -0.710 & 0.47743 \\
\hline bela & 0.15735 & 0.16289 & 1.1704018 & 0.8497303 & 1.6098032 & 0.966 & 0.33407 \\
\hline ıri & 0.77744 & 0.17770 & 2.1758984 & 1.5352874 & 3.0824104 & 4.375 & $\begin{array}{l}1.21 \mathrm{e}- \\
05 * * *\end{array}$ \\
\hline s Ababa & -0.12741 & 0.19557 & 0.8803744 & 0.5983241 & 1.2888041 & -0.651 & 0.51475 \\
\hline Dawa & 0.06499 & 0.18598 & 1.0671515 & 0.7391351 & 1.5332466 & 0.349 & 0.72675 \\
\hline \multicolumn{8}{|c|}{ of place of residence(ref=Urban) } \\
\hline 1 & 0.23243 & 0.10701 & 1.2616596 & 1.0242832 & 1.5583291 & 2.172 & $\begin{array}{l}0.02986 \\
*\end{array}$ \\
\hline
\end{tabular}

kes cigarettes $(\mathrm{ref}=\mathrm{No})$

\begin{tabular}{|l|l|l|l|l|l|l|}
\hline 0.64891 & 0.29215 & 1.91345 & 1.0740949 & 3.3937026 & 2.221 & $\begin{array}{l}0.02634 \\
*\end{array}$ \\
\hline
\end{tabular}

ent marital status(ref= Married or Living with partner)

\begin{tabular}{|c|c|c|c|c|c|c|c|}
\hline $\begin{array}{l}\text { Iwed } \\
\text { ırced/separated }\end{array}$ & 0.34988 & 0.10357 & 1.4188947 & 1.1567564 & 1.7363488 & 3.378 & $\begin{array}{l}0.00073 \\
* * *\end{array}$ \\
\hline \multicolumn{8}{|c|}{ ber of other wives (ref = No other wives) } \\
\hline ther wives & 0.47752 & 0.10353 & 1.6120743 & 1.314742 & 1.9732178 & 4.612 & $\begin{array}{l}3.98 \mathrm{e}- \\
06 * * *\end{array}$ \\
\hline \multicolumn{8}{|c|}{ 'ondent's occupation (grouped) (ref = Not working) } \\
\hline loyed(salary paid) & -0.52772 & 0.23465 & 0.5899483 & 0.3657148 & 0.9204773 & -2.249 & $\begin{array}{l}0.02451 \\
*\end{array}$ \\
\hline shant & 0.12697 & 0.10724 & 1.1353823 & 0.9189643 & 1.3993882 & 1.184 & 0.23643 \\
\hline ler & 0.06229 & 0.09673 & 1.0642744 & 0.8798846 & 1.2857112 & 0.644 & 0.51959 \\
\hline rs & 0.07904 & 0.11872 & 1.0822445 & 0.855926 & 1.3634809 & 0.666 & 0.50557 \\
\hline \multicolumn{8}{|c|}{ sand/partner drinks alcohol (ref= No) } \\
\hline & 0.99024 & 0.08445 & 2.6918727 & 2.2820390 & 3.1778415 & 11.725 & $<2 \mathrm{e}-16$ \\
\hline
\end{tabular}


you ever chewed Chat? $($ ref $=$ No)

\begin{tabular}{|c|c|c|c|c|c|c|c|}
\hline & 0.28518 & 0.11017 & 1.3299958 & 1.0701995 & 1.6485698 & 2.588 & $\begin{array}{l}0.00964 \\
* *\end{array}$ \\
\hline \multicolumn{8}{|c|}{ ber of living children(ref=0) } \\
\hline & 0.31196 & 0.12998 & 1.3661039 & 1.0622291 & 1.7687714 & 2.400 & $\begin{array}{l}0.01639 \\
*\end{array}$ \\
\hline & 0.25908 & 0.13802 & 1.2957318 & 0.9946261 & 1.6977970 & 1.901 & 0.05734 . \\
\hline & 0.52568 & 0.13802 & 1.6916041 & 1.2943589 & 2.2242557 & 3.809 & $\begin{array}{l}0.00014 \\
* * *\end{array}$ \\
\hline \multicolumn{8}{|c|}{ sand's desire for children(ref= Both want same) } \\
\hline sand wants more & 0.16318 & 0.08877 & 1.1772497 & 0.9889775 & 1.4007256 & 1.838 & 0.06604 . \\
\hline sand wants fewer & 0.40272 & 0.13488 & 1.4958932 & 1.1460513 & 1.9453109 & 2.986 & $\begin{array}{l}0.00283 \\
* *\end{array}$ \\
\hline t know & -0.15859 & 0.0902 & 0.853345 & 0.7146105 & 1.0178497 & -1.758 & 0.07874 \\
\hline
\end{tabular}

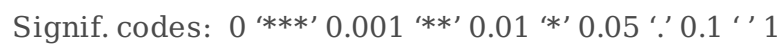

In Table-3, a chi-square test statistic was applied to assess heterogeneity in the proportion of ever married women who have intimate partner violence within regions. The test yield $\chi^{2}=152.8934, \mathrm{~d} . \mathrm{f}=10, \mathrm{P}$-value $<$ 0.001 . Therefore, regions are indeed significantly heterogeneous. Thus, the significance of this test gives us an evidence of heterogeneity of intimate partner violence across regions in Ethiopia. The variance of the random factor is significant which indicates that there is regional variation in intimate partner violence. The significance of the deviance-based chi-square value for the empty model shown implies that an empty model with random intercept is better than an empty model without random intercept. The significant deviance-based chi-square value and smallest AIC for random intercept model indicates that the random intercept and fixed slope model is a better fit as compared to the empty model. Similarly, the deviance-based chi-square test for significance of the random intercept model with the fixed coefficient and random coefficient model indicated that the random intercept model with the fixed coefficient were a better fit compared to the multiple logistic regression model. Therefore, random intercept model is better fitted this data.

Table-3: Multilevel logistic regression model comparison 


\begin{tabular}{|l|l|l|l|}
\hline & Null model & Random intercept model & Random coefficient model \\
\hline$-2 *$ loglikelihood & 5255.201 & 5001.462 & 4999.45 \\
\hline Deviance based chi-square test & 152.8934 & 118.3081 & 125.011 \\
\hline P-value & & & $2.270592 \mathrm{e}-104^{* * *}$ \\
\hline \multicolumn{4}{|l|}{ Model Fit Diagnostics } \\
\hline AIC & 5259.201 & 5037.462 & 5045.45 \\
\hline BIC & 5272.12 & 5153.734 & 5194.02 \\
\hline
\end{tabular}

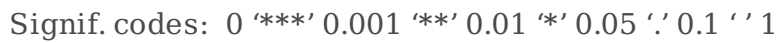

In table-4, the intercept $\beta_{0}=-1.1160$ interpreted as the odds of intimate partner violence in an average region. That is the intercept informs us that the average probability of intimate partner violence everywhere in Ethiopia is 0.246754 . The intra-region correlation obtained from the empty model with random effect was 0.0215 . This value is called the intra class correlation coefficient (ICC) and interpreted as $2.15 \%$ of the variation in the intimate partner violence can be explained by grouping every married woman with respect to their region. The remaining $97.85 \%$ of the variation of intimate partner violence is explained within region-lower level units.

Table-4. Results for multilevel logistic regression model without explanatory variables

\begin{tabular}{|l|l|l|l|l|}
\hline Fixed part & Coefficient & S.E. & Z-value & $\operatorname{Pr}(>|\mathrm{z}|)$ \\
\hline$\beta_{0}$-intercept & -1.1160 & 0.1429 & -7.811 & $5.68 \mathrm{e}-15 * * *$ \\
\hline \multicolumn{3}{|l|}{} \\
\hline Random part & Estimate & S. E. & \multicolumn{1}{|l|}{ Wald test of 95\% CI } \\
\hline Between -Region variance $\delta^{2}{ }_{0}=\operatorname{var}\left(U_{o j}\right)$ & 0.0724113 & 0.002433671 & 0.0459518 & 0.1141063 \\
\hline Deviance based chi-square 152.8934 & p-value $=3.435549 \mathrm{e}-134 * * *$ \\
\hline
\end{tabular}

In Table-5 for It indicated that intimate partner violence variations among regional states of Ethiopia were non-zero. The random effects indicates that between region variance, the intimate partner violence is estimated as $\delta^{2}=0.066$ and the variance between each respondent within the region is estimated as $=3.29$. Then, the total variance equals to 3.356 . This shows that $1.97 \%$ of the variance in the intimate partner violence can be attributed to difference between regions. The random intercept and fixed slope logistic regression model is a multilevel model which have random intercept and fixed coefficient of predictors. As can be seen from Table- 5, the analysis of multilevel logistic regression revealed that intimate partner violence in ever married women varied among regions. The result displayed that the region-wise difference in intimate partner violence was statistically significant. In addition, husband's desire for children, number of living children, women ever chewed chat, husband/partner drinks alcohol, respondent's occupation, number of other wives, current marital status, women smoke cigarettes, type of place of residence were also found to be significant determinants of variation in intimate partner violence 
among the regions. The estimated coefficients and odds ratio had similar interpretation with that of single level logistic regression analysis.

Table-5: Results of random intercept and fixed coefficient logistic regression model

\begin{tabular}{|c|c|c|c|c|}
\hline Fixed effect & B & S.E. & Z-value & P-value \\
\hline Intercept & -2.10713 & 0.20029 & -10.520 & $<2 \mathrm{e}-16 * * *$ \\
\hline \multicolumn{5}{|c|}{ Type of place of residence(ref=Urban) } \\
\hline Rural & 0.22372 & 0.10532 & 2.124 & $0.033649 *$ \\
\hline \multicolumn{5}{|l|}{ Smokes cigarettes(ref=No) } \\
\hline Yes & 0.65533 & 0.29175 & 2.246 & $0.024691 *$ \\
\hline \multicolumn{5}{|c|}{ Current marital status (ref= Married or Living with partner) } \\
\hline Widowed /divorced/separated & 0.34872 & 0.10335 & 3.374 & $0.000741 * * *$ \\
\hline \multicolumn{5}{|c|}{ Number of other wives (ref $=$ No other wives) } \\
\hline 1-6 other wives & 0.46438 & 0.10301 & 4.508 & $6.54 \mathrm{e}-06 * * *$ \\
\hline \multicolumn{5}{|c|}{ Respondent's occupation (grouped) (ref = Not working) } \\
\hline Employed (salary paid) & -0.52444 & 0.23444 & -2.237 & $0.025283 *$ \\
\hline Merchant & 0.12826 & 0.10696 & 1.199 & 0.230450 \\
\hline Farmer & 0.07280 & 0.09637 & 0.755 & 0.450006 \\
\hline Others & 0.08456 & 0.11860 & 0.713 & 0.475857 \\
\hline \multicolumn{5}{|c|}{ Husband/partner drinks alcohol (ref= No) } \\
\hline Yes & 0.99561 & 0.08389 & 11.868 & $<2 \mathrm{e}-16 * * *$ \\
\hline \multicolumn{5}{|c|}{ Have you ever chewed Chat? (ref= No) } \\
\hline Yes & 0.31048 & 0.10993 & 2.824 & $0.004740 * *$ \\
\hline \multicolumn{5}{|l|}{ Number of living children (ref=0) } \\
\hline $1-2$ & 0.31490 & 0.12981 & 2.426 & $0.015276 *$ \\
\hline $3-4$ & 0.26051 & 0.13611 & 1.914 & 0.055621 \\
\hline $5+$ & 0.52123 & 0.13775 & 3.784 & $0.000154 * * *$ \\
\hline \multicolumn{5}{|c|}{ Husband's desire for children (ref= Both want same) } \\
\hline Husband wants more & 0.15934 & 0.08857 & 1.799 & 0.072007 \\
\hline Husband wants fewer & 0.40306 & 0.13474 & 2.991 & $0.002778 * *$ \\
\hline Don't know & -0.15387 & 0.09009 & -1.708 & 0.087640 \\
\hline Random part & Estimate & S.E. & \multicolumn{2}{|c|}{ Wald test of $95 \%$ CI } \\
\hline $\begin{array}{l}\text { Random intercept } \\
\delta^{2}{ }_{0}=\operatorname{var}\left(U_{o j}\right)\end{array}$ & 0.06614167 & 0.002433671 & 0.04140978 & 0.1056446 \\
\hline
\end{tabular}

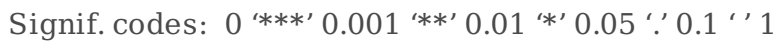

\section{Discussion}

The study examined the prevalence of intimate partner violence and associated factors in Ethiopia based on an evidence from Ethiopia Demographic and Health Survey, 2016. In this study, among ever-married women who have been participated in this study, $22.3 \%, 7.6 \%$ and $6.1 \%$ of women have experienced emotional, sexual and physical violence respectively. The prevalence of intimate partner violence was found to be $25.6 \%$. This finding belongs in the range of $20 \%$ to $78 \%$ prevalence of intimate partner violence in Ethiopia [4].It is lower than a World Health Organization 30\% global report of intimate partner violence[3], a 36\% finding in sub-Saharan Africa [18] and 33\% report in European member 
countries[19].But, it is higher than a study finding in Nigeria(15.2\%)[20] and Spain (12.2\%)[21].This might be attributed to a difference in the study period, population and area.

This study also found that women in Harari region were more likely to experience intimate partner violence than Tigray region. Women in Afar and Somali regions have been less likely to have intimate partner violence than Tigray region. But, women's experience of intimate partner violence in Amhara, Oromia, Southern Nations Nationalities and Peoples Region, Benishangul-Gumuz, Gambella, Addis Ababa and Dire Dawa regions were not significantly different from women in Tigray region. Such regional variations in women's experience of intimate partner violence is consistent with studies conducted in Nigeria [20] and Spain [21].The regional disparities in prevalence of intimate partner violence could be attributed to the difference in socio-economic, cultural and life style condition of the women in these respective regions.

Those women living in the rural areas were more likely to have intimate partner violence as compared to those living in the urban areas. It is consistent with previous studies [4, 22-25].This may be attributed that those women from rural areas may not have access to an information related with the issue.

Employed women were less likely to experience intimate partner violence compared to those not employed. This is in line with a finding of a systematic review in Ethiopia which showed that employed women had $60 \%$ higher odds of violence than unemployed women[4]. Those ever-married women who were not living together with their partners were more probably to experience violence as compared to their counter parts.

Those women whose husbands drink alcohol were more likely to experience domestic violence than their counter parts. It is consistent with different studies [22, 23, 26-29]. This could be happened due to the conflict arisen between women and husbands in financial management, work and sexual relationship. On the other hand, women who smoke cigarettes were at increased risk of violence by their intimate partners. It is comparable with a study conducted in Gedo Town[30]. Those women who chewed chat were more likely to experience violence than their counterparts. This could be explained by the fact that women engaged in such activities might push them to encounter conflicts with their husbands.

Women with their husband's desire for children wants fewer were more likely to have violence compared to the same desire for children by both the women and husbands. Similarly, women with number of living children $1-2$, and $5+$ were more likely to experience intimate partner violence compared to women with no number of living children. It is consistent with a study in Nigeria[31].In addition, women with their husbands having 1-6 other wives were more likely to experience violence than women with their husbands had no other wives. It is also consistent with studies[20,23]. This might be attributed to a conflict arise when the husband/partner has communication with other wives.

Due to the cross-sectional nature of the study, there was a difficulty of establishing the casual relationship between the outcome and independent variables. Recall bias about women's experience of 
intimate partner violence could be a limitation. In addition, violence related issues are very sensitive and there might be under-reporting of the situation by respondents.

\section{Conclusion}

The study finding showed that more than 1 in 4 ever married women in Ethiopia have experienced violence from their intimate partners. Intimate partner violence varies across regions in Ethiopia. Husband's desire for children, number of living children, women ever chewed chat, husband/partner drinks alcohol, respondent's occupation, number of other wives, current marital status, smoking cigarettes, type of place of residence were found to be significant determinants of intimate partner violence. The government's effort towards elimination of violence against women should be well strengthened by addressing intimate partner violence disparity in Ethiopian regions and also taking in to account identified factors of intimate partner violence by this study.

\section{Abbreviations}

AIC: Akaike Information Criteria; BIC: Bayesian Information Criteria; WHO: World Health Organization; GTP: Growth and Transformation Plan; DHS: Demographic and Health Survey; EDHS: Ethiopia Demographic and Health Survey; SNNPR: Southern Nations, Nationalities and Peoples Region; OR: Odds Ratio; Cl: Confidence Interval

\section{Declarations}

Ethics approval and consent to participate: Not applicable.

Consent for publication: Not applicable.

Availability of data and materials: The dataset used and/or analyzed during the current study is available from the corresponding author on reasonable request.

Competing interests: The authors declare that they have no competing interests.

Funding: No funding was received for this study.

\section{Author's contributions}

MS conceived, designed the study and performed the data analysis and interpretation assisted in designing the study, data analysis and interpretation. MS drafted the manuscript, read and approved the final manuscript.

Authors' information: Not applicable.

Acknowledgements 
The authors would like to acknowledge Measure Demographic and Health Survey for providing online permission to use the Ethiopia Demographic and Health Survey 2016 data set.

\section{References}

1. Nations, U., Declaration on the elimination of violence against women . New York: UN. 1993.

2. Organization, W.H., Understanding and addressing violence against women: Sexual violence. 2012.

3. Organization, W.H., Global and regional estimates of violence against women: prevalence and health effects of intimate partner violence and non-partner sexual violence. 2013: World Health Organization.

4. Semahegn, A. and B. Mengistie, Domestic violence against women and associated factors in Ethiopia; systematic review. Reproductive health, 2015. 12(1): p. 78.

5. Duvvury, N., et al., Intimate partner violence: Economic costs and implications for growth and development. 2013.

6. Dillon, G., et al., Mental and physical health and intimate partner violence against women: A review of the literature. International journal of family medicine, 2013. 2013.

7. Godoy-Ruiz, P., et al., Intimate partner violence and depression among Latin American women in Toronto. Journal of immigrant and minority health, 2015. 17(6): p. 1771-1780.

8. Maxwell, L., et al., Estimating the effect of intimate partner violence on women's use of contraception: a systematic review and meta-analysis. PloS one, 2015. 10(2): p. e0118234.

9. Mohammed, B.H., et al., Intimate partner violence and utilization of maternal health care services in Addis Ababa, Ethiopia. BMC health services research, 2017. 17(1): p. 178.

10. Assembly, U.G., Convention on the elimination of all forms of discrimination against women. Retrieved April, 1979. 20: p. 2006.

11. Union, A., Protocol to the African Charter on Human and People's Rights on the Rights of Women in Africa. 2003.

12. Ethiopia, F.D.R.o., The Revised Criminal code Proclamation No.414/2004. 2004.

13. Ethiopia, N.P.C.o.t.F.D.R.o., The Second Growth and Transformation Plan(GTP II)(2015/16-2019/20). 2015.

14. ICF, C.S.A.C.o.E.a., Ethiopia Demographic and Health Survey 2016.

15. Guo, G. and H. Zhao, Multilevel modeling for binary data. Annual review of sociology, 2000. 26(1): p. 441-462.

16. Snijders, T., Bosker, RJMultilevel analysis. An introduction to basic and advanced multilevel modeling, 1999.

17. Gelman, A. and J. Hill, Data analysis using regression and multilevel/hierarchical models. 2006: Cambridge university press. 
18. Sheila Young Steinbrenner PhD, R., Determinants of intimate partner violence in Sub-Saharan Africa: a review of prevention and intervention programs. Partner abuse, 2016. 7(3): p. 277.

19. FRA, E., Violence Against Women: An EU-Wide Survey. Main Results Report, 2014, Vienna: European Union Agency for Fundamental Rights. Available at: http://fra. europa. eu/en/publication/2014/violence-against-women-eu-widesurvey-main-results-report.

20. Oyediran, K.A. and B. Feyisetan, Prevalence and contextual determinants of intimate partner violence in Nigeria. African Population Studies, 2017. 31(1).

21. Sanz-Barbero, B., et al., Intimate partner violence among women in Spain: the impact of regional-level male unemployment and income inequality. The European Journal of Public Health, 2015. 25(6): p. 1105-1111.

22. Semahegn, A., T. Belachew, and M. Abdulahi, Domestic violence and its predictors among married women in reproductive age in Fagitalekoma Woreda, Awi zone, Amhara regional state, North Western Ethiopia. Reproductive health, 2013. 10(1): p. 63.

23. Abeya, S.G., M.F. Afework, and A.W. Yalew, Intimate partner violence against women in western Ethiopia: prevalence, patterns, and associated factors. BMC public health, 2011. 11(1): p. 913.

24. Bifftu, B.B., et al., Domestic Violence among Pregnant Mothers in Northwest Ethiopia: Prevalence and Associated Factors. Advances in Public Health, 2017. 2017.

25. Mavrikiou, P.M., M. Apostolidou, and S.K. Parlalis, Risk factors for the prevalence of domestic violence against women in Cyprus. The Social Science Journal, 2014. 51(2): p. 295-301.

26. Regassa, N., Intimate partners' violence in Southern Ethiopia: Examining the prevalence and risk factors in the Sidama zone. International Journal of Sociology and Anthropology, 2012. 4(1): p. 13.

27. Tilahun, T. and A. Hailemariam, Correlates of Domestic Violence against Women in Bahr Dar, Amhara Region, Ethiopia. Ethiopian Journal of Development Research, 2006. 28(2): p. 31-61.

28. Yigzaw, T., A. Yibric, and Y. Kebede, Domestic violence around Gondar in northwest Ethiopia. Ethiopian Journal of Health Development, 2004. 18(3): p. 133-139.

29. Adogu, P.O.U., et al., Factors associated with intimate partner violence among wives of military and civilian men in Abuja Nigeria. Sociology mind, 2015. 5(02): p. 61.

30. Demissie, D.B., K. Abduro, and H. Teklu, Intimate Partner Violence against Married Women and Associated Factors in Gedo Town, Oromia, Ethiopia.

31. Solanke, B.L., A.L. Bisiriyu, and A. Oyedokun, Is the likelihood of spousal violence lower or higher among childless women? Evidence from Nigeria demographic and health surveys. BMC women's health, 2018. 18(1): p. 20.

\section{Note Regarding Table 6}

Table 6 is only available as a download in the supplemental files section

\section{Supplementary Files}


This is a list of supplementary files associated with this preprint. Click to download.

- table6.docx 